\title{
From environmental knowledge to encouraging pro-environmental behavior for air pollution control in Isfahan: a highly air-polluted city in central Iran
}

\author{
Mojtaba Jokar ${ }^{1} \cdot$ Zahra Razavi $^{1} \cdot$ Hossein Moradi $^{1}$
}

Received: 5 February 2020 / Accepted: 28 October 2020 / Published online: 11 November 2020

(c) Springer Nature Switzerland AG 2020

\begin{abstract}
Isfahan is a historical city with UNESCO registered World Heritage suffering from air pollution as the major environmental challenge. The present research aims to assess the social and environmental concerns associated with air pollution in Isfahan via exploring the relationship between effective parameters on environmentally friendly behavior among Isfahanian citizens using factor analysis. A questionnaire including the citizens' knowledge and their experience on air quality impacts, as well as their perception about the level of air pollution, the pollution sources, and its control and selfprotection actions was designed and applied to a sample of 388 individuals. The results showed the dried river-substrate of Zayandehroud river, followed by improper municipal management, and the high number of vehicles and mega-industries are the most important contributing factors to air pollution, respectively. These findings were corroborated through correlation analysis between mean AQI values and responses. The findings indicated that people's awareness about air pollution, its impacts, and their willingness-to-pay for reducing air pollution are increasing as the education attainment increases. Improving the quality of gasoline and the cars as well as developing the public transportation were the main requests of Isfahanian citizens from managers and decision-makers for air pollution mitigation. We conclude that the pro-environmental behaviors of people significantly depend on their perception of air pollution as public engaging in air pollution control plans will be obtained by an increase of their awareness about air quality status, its health-related consequences, and high level of citizen's responsibility.
\end{abstract}

Keywords Air pollution · Public perception and responsibility · Questionnaire · Air quality index (AQI) · Proenvironmental behavior

\section{Introduction}

Air pollution is one of the most salient concerns of the present human population, which emerges as a byproduct of climate change, population growth, urbanization, increasing vehicle numbers, and industrialization [1, 2]. Human intervention has a major share of environmental degradation and contributing to air pollution. Therefore, improving human attitudes and behaviors may play a key role in environmental protection [3]. However, less attention has been paid to the individual and public role in environmental protection [4]. All human-beings can intuitively become aware of air pollution through annoyance and symptoms experience (e.g., fatigue, headache, dust, soot, dirtiness, irritation of the eyes, nose, or throat and respiratory diseases). This ability has been acknowledged as a useful indicator to get an understanding of air pollution $[1,5,6]$. Individuals and communities may help significantly to reduce air pollution levels and its following impacts [7]. If a long-term air quality improvement

Hossein Moradi, hossein.moradi@iut.ac.ir | 'Department of Natural Resources, Isfahan University of Technology, 8415683111 Isfahan, Iran. 
is pursued, a change in the behavior of every individual with their environment (referred to pro-environmental behavior) would be a major step toward meeting this goal $[1,8,9]$ that it would be occurred via an increase of public participation as an essential prerequisite for successful environmental management $[7,10]$. Participation gives individuals an important sense of self and a dependence on the environment they live in [3].

Generally, three behavioral states are associated with air pollution management: (1) actions for raising public awareness as well as the level of information and knowledge about the quality and quantity of air pollution and their commitments, (2) large-scale actions for reducing air pollution such as limited use of transportation, and (3) fine-scale actions (i.e., self-protection) to minimize the impacts of air pollution such as reducing outdoor activities [7].

To better understanding of environmental behaviors of people about air pollution, evaluation of social and psychological dimensions of air pollution is necessary. Perception (referred to insights into the main dimensions of air pollution), intentions (willingness to protect the environment), awareness, health-related concern, and habits. In fact, the attitude and perceptions of people regarding the consequences of air pollution determine pro-environmental behavior [7, 11-13]. The personal knowledge (understanding about different pollutants, causes of air pollution, etc.), capabilities, incentives, and the conditions governing the society are other contributing factors in pro-environmental behavior $[7,14]$.

Several research works confirmed that attitude, intention, and responsibility of people have significant effects on their pro-environmental behaviors. For example, Moradhaseli et al. [15] showed that the students' environmental behavior was intensively influenced by the environmental attitude, perceived behavioral control, and environmental behavior intention. Levine and Strube [16] found that intentions and knowledge significantly and independently predicted pro-environmental behaviors so that knowledge was a direct cause of behavior whereas the attitudes were assumed to influence behavior through intentions. Seif and Nematolahi [3] indicated that environmental concern, attitude, and knowledge have a direct influence on pro-environmental behaviors. Also, increasing people's environmental responsibility improved people's environmental attitude and knowledge to environmentally friendly behavior. Abolhassani et al. [17] found that for the development or introduction of an environmentally friendly behavior such as bicycle sharing system (BSS) as an alternative mode of urban transportation, paying attention to public preferences and needs is the first priority.

\section{SN Applied Sciences}

It is proven by some studies that informing citizens about air quality status and the associated adverse impacts promotes their motivation and engagement in pro-environmental behavior and lifestyle choices [18-20] as a gap is expected between people's perception and what exists in reality (quantitative measurements) [21]. It seems that the main step to managing air pollution in large cities is to provide solutions aimed at exploring and regulating people's perspectives regarding air pollution. In fact, governmental efforts to enhance air quality can be accompanied by an improved understanding of the awareness and their support for environmental protection among the citizens in large cities [22].

In recent years, Isfahan, as a large city with about two million inhabitants, has ranked as one of the most polluted cities of Iran owing to the influence of a number of pervasive factors such as high population, drought, having the second largest number of cars and motorcycles after Tehran City (the capital of Iran), extensive built-up construction, and increasing development of small- to large-scale industries which made it the second most industrialized city of Iran after Tehran [23-25]. These factors are major drivers of air pollution, thereby underscoring the importance of assessing various aspects of air pollution in this city.

The main objectives of this research including (1) to investigate the air pollution burden perceived by Isfahan citizens, their knowledge and experience of air quality impacts as well as their incentives and responsibilities to air pollution control; (2) to study the main causes of Isfahan air pollution from the public's views and prioritize it to facilitate providing strategies to reduce air pollution by decision-makers; (3) to evaluate the air quality status in Isfahan scientifically and sensibly by integrating air quality index (AQI) data and the results of a questionnaire-based survey; (4) to provide a reasonable insight into the social and environmental concerns associated with air pollution to help the managers and decision-makers to manage air pollution quality in Isfahan city.

\section{Materials and methods}

\subsection{Study area}

Isfahan City, with an approximate area of $550 \mathrm{~km}^{2}\left(32^{\circ}\right.$ $38^{\prime} \mathrm{N}$ longitude and $51^{\circ} 38^{\prime} \mathrm{E}$ latitude), is located on the bank of Zayandehroud River in the central part of the plateau of Iran. It has an annual average rainfall of $122.1 \mathrm{~mm}$ and an average temperature of $16.2^{\circ} \mathrm{C}$ [26]. According to the census bureau data in 2011, Isfahan has an estimated population of 1,908,968 inhabited in 15 municipal districts, making it the third most-populated city of Iran 
behind Tehran and Mashhad [27](Fig. 1). There are more than a million vehicles using diesel, gasoline, and natural gas in Isfahan. This city is known as the largest industrialized region in Iran, where there are many industries and companies within a buffer of $50 \mathrm{~km}[28,29]$. The other factor influencing air pollution is air consistency and inversion events in Isfahan. Because of the Special climatic condition of Isfahan, the number of inversion events is frequent (about $72 \%$ of the days of the year) [26].

\subsection{Sampling procedure}

A classified sampling method was employed in this research. The study sample size was determined using the Cochran formula (Eq. 1), in which having a knowledge of the society's case study attribute plays a pivotal role in determining sampling size [30].

$n=\left(z^{2} p q / d^{2}\right) /\left(1+1 / N\left(z^{2} p q / d^{2}-1\right)\right)$

In this method, $N$ is the population size, $n$ is the sample size, $q=1-p$ is the proportion of an attribute that is absent in the population (e.g., the men's population), $p$ is the proportion of an attribute that is present in the population (e.g., the women's population), $z$ is the critical value of the desired confidence, and $d$ is the desired level of precision. Regarding the number of members in each class and the total sample size, the required sample size was then calculated using Eq. 2.

$n_{h} / n=N_{h} / N$

where $N$ is the total population size, $\mathrm{n}$ is the total sample size, $n_{h}$ is the sample size in each class, and $N_{h}$ is the total size of each class. Subsequent to determining the sample size in each class, a non-replacement random sampling procedure proportional to the total size was employed to select samples from each neighborhood (class). The studied population comprised 388 members, all above 15 years old, who live or work in Isfahan City. Table 1 gives a summary of the studied statistical population in this research.

\subsection{Questionnaire}

The questionnaire was designed (Appendix Table 12) based on the experts' opinions (Department of Natural Resources, Isfahan University of Technology) and related studies on public views about environmental problems especially air pollution in other countries which were modified to the case of Isfahan city $[1,4,15,31]$. The questions were divided into seven sections: personal information; knowledge about air pollution, public understanding
Fig. 1 Geographic location of Isfahan City and 15 municipal districts

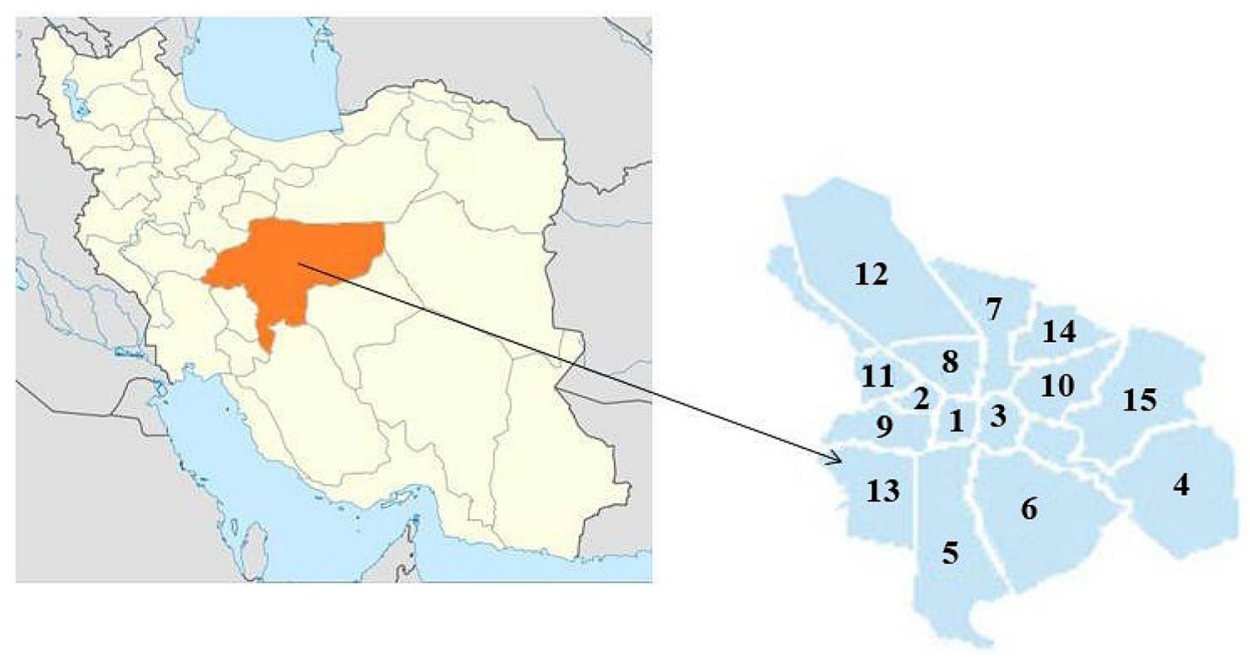

Table 1 Sample demographics including frequency (\%)

\begin{tabular}{|c|c|c|c|c|c|c|c|}
\hline \multicolumn{2}{|c|}{ Vehicle type } & \multicolumn{2}{|c|}{ Education level } & \multicolumn{2}{|c|}{ Age (year) } & \multicolumn{2}{|l|}{ Sex } \\
\hline$\%$ & Type & $\%$ & Level & $\%$ & Class & $\%$ & Class \\
\hline 17 & No vehicle & 9.5 & Under diploma & 5.5 & $<20$ & 53.4 & Male \\
\hline 60 & Car & 43.2 & $\begin{array}{l}\text { Diploma Advanced } \\
\text { diploma }\end{array}$ & 67.6 & $20-40$ & 46.6 & Female \\
\hline 17 & Motorcycle & 37.8 & $\mathrm{BSC}$ & 23.4 & $40-60$ & & \\
\hline 6 & Bicycle & 9.5 & MSc, PhD & 3.5 & $>60$ & & \\
\hline
\end{tabular}


and culture; air pollution sources; executive and municipal management-formation and organization-rules and regulations; the impacts of air pollution; solutions for improving environmental quality and responsibility for controlling air pollution. Some questions were designed to draw out categorical responses: very low, low, medium, high, and very high as well as scores ranging from 1 to 5. All questions were to gauge the people's perspective, but not just to get simple yes or no answers. The questionnaires were distributed among the people of different neighborhoods independently at the 15 municipal districts of Isfahan from 2016 to 2017 and filled in without specifying a certain completion time limit. To observe ethical points, the questionnaires were completed anonymously and people were quite willing to participate in the survey.

\subsection{Correlation of results of survey with air quality level}

Air quality index (AQI) data were obtained from the Isfahan Department of Environment (Isfahan DoE) for the period 2008-2017. AQI is being calculated in seven air quality monitoring based on the concentration of five conventional air pollutants including ground-level ozone, particulate matter, carbon monoxide, sulfur dioxide, and nitrogen dioxide. The mean AQI values (continuous values) from the air pollution monitoring sites were used in this research. AQI values are classified as good $(0-50)$, moderate (51-100), unhealthy (101-150) for sensitive groups, unhealthy (151-200), very unhealthy (201-300), and hazardous (300-500) [32, 33]. AQI was used to evaluate the accuracy of information obtained from the questionnaire as well as determine the association of the people's understanding about air pollution as AQI values are changing.

\subsection{Statistical analysis}

Prior to statistical analysis, it was imperative to ensure high correlation coefficients between the responses given to each question of the questionnaire. The results of Bartlett's test and Kaiser-Meyer-Olkin (KMO) index confirmed the sufficiency of the correlation coefficients between the questions and justified the possibility of performing statistical analysis ( $\mathrm{KMO}=0.627$, Bartlett's test $=5732.490$ $\mathrm{DF}=1830, P$-Value $<0.0001)$. The internal homogeneity of the questionnaire was tested by measuring Cronbach's alpha index which should be above 0.7 to be acceptable. In this research, the Cronbach's alpha index achieved a satisfactory value of 0.755 .

Descriptive analysis and chi-square tests were performed to estimate the association between public concerns about air quality and influencing parameters such as individual perception, incentives, knowledge, and their responsibility to (on) air pollution control. Factor analysis was made to determine influencing factors on the increase of air pollution from people's point of view. This technique evaluates and classifies the variations of all data group parameters, and determines the degree of influence of factors by establishing a new relationship set of variables that may explain variations in the original data set $[34,35]$. Factor analysis produces factor loadings which can be interpreted as a correlation between the responses and the factors [36]. Factor analysis was performed using principal component analysis (PCA) followed by a varimax orthogonal rotation. Subjects of questionnaire that were analyzed using factor analysis comprised the following: (1) air pollution sources, (2) executive and municipal management-formations and organizations-rules and regulations, (3) solutions for improving air pollution condition, (4) responsibility to control air pollution condition, and (5) satisfaction of the performance of sections involved in air pollution abatement. Significant loading (correlation of questionnaire responses with factors) was considered to be greater than 0.40 [37]. Regression analysis was also adopted to assess the correlation between continuous values of AQI (annual average) and questionnaire responses. Analyses were conducted using SPSS version 23 (IBM, Chicago, IL, USA).

\section{Results}

\subsection{The awareness level of Isfahanies about air pollution}

A number of 388 persons, aged 14-73, including 153 women (39.84\%), 231 men (60.16\%), and 4 genderunknown persons participated in the research. The results showed a significant difference in the awareness level between genders (Table 2 ) so that $83.48 \%$ of men and $76.47 \%$ of women stated that the air pollution level in Isfahan is high and very high $(\chi 2=3.654, P$-Value $=0.089$ ). More precisely, $49.02 \%$ of women, compared to $42.87 \%$ of men, believed that air pollution of Isfahan is high. On the other hand, however, $42.61 \%$ of men, compared to $27.46 \%$ of women, categorized it as very high $(\chi 2=10.549$, $P$-Value $=0.032$ ). Despite finding an insignificant relationship between education level and air quality condition (Table 2), reflecting the similar tangibility of air pollution to approximately all people, the frequency of responses showed that educated people (BSc or higher) aged from 20 to 40 have developed a better awareness of air pollution.

In addition, the results of assessing the awareness of Isfahanies across the 15 municipal districts showed that nearly $90 \%$ of those inhabiting the central part of the city 
Table 2 Awareness level of Isfahanies about air pollution

\begin{tabular}{lcl}
\hline Variables & Low to moderate (\%) & High to very high (\%) \\
\hline $\begin{array}{l}\text { Gender } \\
\text { Female }\end{array}$ & \\
Male & $36(23.53)$ & $117(76.47)$ \\
$\chi^{2}=2.895 ; P$-Value $=0.089$ & $192(83.48)$ \\
Age & \\
$\leq 20$ & $10(27.78)$ & $26(72.22)$ \\
$20-40$ & $49(21.03)$ & $184(78.97)$ \\
$40-60$ & $14(15.56)$ & $76(84.44)$ \\
$>60$ & $1(8.33)$ & $11(91.67)$ \\
$\chi^{2}=3.654 ; P$-Value $=0.301$ & \\
Education & & $144(82.29)$ \\
$\leq$ diploma & $31(17.71)$ & $163(78.74)$ \\
$\geq$ College & $44(21.26)$ & \\
$\chi^{2}=0.754 ; P$-Value $=0.385$ & \\
\hline
\end{tabular}

Table 3 Awareness level of Isfahanies about air pollution across the 15 municipal districts of Isfahan

\begin{tabular}{llll}
\hline District No & Low to moderate (\%) & High (\%) & Very high (\%) \\
\hline 1 & $3(15.00)$ & $9(45.00)$ & $8(40.00)$ \\
2 & $2(20.00)$ & $3(30.00)$ & $15(50.00)$ \\
3 & $2(7.41)$ & $10(37.04)$ & $15(55.56)$ \\
4 & $5(21.74)$ & $8(34.78)$ & $10(43.48)$ \\
5 & $12(33.33)$ & $7(19.44)$ & $17(47.22)$ \\
6 & $3(10.71)$ & $16(57.14)$ & $9(32.14)$ \\
7 & $3(9.68)$ & $23(74.19)$ & $5(16.13)$ \\
8 & $10(24.39)$ & $17(41.46)$ & $14(34.15)$ \\
9 & $2(12.50)$ & $7(43.75)$ & $7(43.75)$ \\
10 & $5(14.29)$ & $21(60.00)$ & $9(25.71)$ \\
11 & $1(11.11)$ & $5(55.56)$ & $3(33.33)$ \\
12 & $9(37.50)$ & $6(25.00)$ & $9(37.50)$ \\
13 & $2(9.09)$ & $14(63.64)$ & $6(27.27)$ \\
14 & $10(25.64)$ & $11(28.21)$ & $18(46.15)$ \\
15 & $6(24.00)$ & $12(48.00)$ & $7(28.00)$ \\
\hline
\end{tabular}

(districts 1 and 3) were bothered by air pollution. In other parts of the city including central to northern and northwestern districts of 12,8 , and 7 , western and southwestern districts of 5 and 13 , and eastern to northeastern districts of 15,14 , and 10 , the majority of citizens (60-90\%) categorized air pollution as high and very high $(\chi 2=51.485$, $P$-Value $=0.004, \mathrm{DF}=28)($ Table 3$)$. Notable results were also obtained regarding the awareness and attention of Isfahanies about diurnal changes in air quality so that about $80 \%$ of respondents felt a higher air pollution level during summer and winter compared to other seasons. Furthermore, they stated that air pollution escalates during the early morning, noon, and more particularly in the afternoon.

\subsection{The relationship between education and willingness-to-pay for reducing air pollution}

The results showed that $60 \%$ of citizens spend a short to medium time to read and converse with family members and surrounding people about air pollution. Also, the ChiSquare results showed that a significant difference exists between education level and willingness-to-pay for reducing air pollution $\left(P\right.$-Value $\left.<0.0001, \chi^{2}=17.930\right)$ so that 138 (79.77\%) out of all respondents with a diploma or lower degree were willing to pay medium and low prices for reducing air pollution whereas only 35 (20.33\%) of them were willing to pay high prices. Whilst, 122 (59.51\%) out of all high educated respondents (BSC and higher levels) indicated that they are willing to pay the same prices, compared to $83(40.49 \%)$ of them which had a willingness-to-pay of high prices. This shows a straight alignment between education level, which has the ability to raise awareness about irreversible air pollution-induced health and economic damages, and willingness-to-pay for improving air quality.

\subsection{People's perspectives on air pollution management in Isfahan}

Subsequent to assessing the awareness level of Isfahanies about air pollution, statistical analysis was performed on responses given to the specialized, categorized questions about air pollution, source identification, executive management, air pollution control and improvement, the responsibility of people and managers about air pollution, and the people's satisfaction from the performance of sections involved in air pollution abatement.

After ensuring the internal homogeneity of the questionnaire, factor analysis with principal components method and varimax rotation was conducted on the responses. A number of 16 items were extracted by considering those which had an Eigenvalue of one or more. They collectively accounted for $67.23 \%$ of the variance in the questionnaire. To obtain a more simplified structure, factor analysis was performed separately on the responses given to each section of the questionnaire. Table 4 shows the findings from questions about air pollution sources. It was found that $70.20 \%$ of variations were explained by the below-mentioned three main factors:

The first factor included drying up of the Zayandehroud River and the arid- warm climate of Isfahan that explain $24.23 \%$ of variations. Based on the results of Chi-square, 
Table 4 Factor loadings of air pollution sources after the varimax rotation

\begin{tabular}{|c|c|c|c|}
\hline \multirow[t]{2}{*}{ Item } & \multicolumn{3}{|c|}{ Component } \\
\hline & 1 & 2 & 3 \\
\hline Industries & 0.091 & -0.053 & 0.806 \\
\hline Poor-quality gasoline and cars and the high number of vehicles & 0.021 & -0.056 & 0.821 \\
\hline $\begin{array}{l}\text { Improper municipal management, poor performance of available structures (such as universities and } \\
\text { broadcasting companies) }\end{array}$ & -0.048 & 0.831 & -0.082 \\
\hline Non-compliance with environmental laws and Regulations as well as public culture in using vehicles & -0.002 & 0.843 & -0.029 \\
\hline Drying up of Zayandehroud River & 0.853 & -0.089 & 0.014 \\
\hline Arid-warm climate of Isfahan & 0.846 & 0.038 & 0.103 \\
\hline
\end{tabular}

Table 5 Factor loadings of executive and municipal management after the varimax rotation

\begin{tabular}{lrr}
\hline Item & \multicolumn{2}{c}{ Component } \\
\cline { 2 - 3 } & 1 & \multicolumn{1}{c}{2} \\
\hline Gasoline quality & 0.705 & -0.105 \\
Quality of manufactured cars & 0.745 & -0.135 \\
Closure of large industries & -0.045 & 0.973 \\
Suitability of the approved rules and Regu- & 0.719 & 0.212 \\
$\quad$ lations for air pollution abatement & & \\
Enforcement guarantee of rules & 0.839 & -0.044 \\
\hline
\end{tabular}

the frequency of respondents who gave high importance to these items was $45.34 \%$ and $26.42 \%$, respectively.

The second factor comprised improper municipal management, poor performance of available public organizations (such as universities and broadcasting companies), and non-compliance with environmental laws and regulations as well as public habits in using vehicles and accounted for a share of $23.59 \%$ of variations. Also, the frequency of respondents who responded very high to non-compliance to laws and municipal management was $20.4 \%$ and $12.89 \%$, respectively (according to the results of (hi-square).

The third factor included large industries as well as poor-quality gasoline and cars and the high number of vehicles which contributed to $22.38 \%$ of variations in factor analysis whereas had a high importance to $52.49 \%$ and $45.6 \%$ of respondents, respectively.

It was found that natural factors such as drying up of Zayandehroud River and arid-warm climate of Isfahan had the highest load and variations contribution to the first factor. Improper municipal management and increasing number of vehicles and industries were found with a small difference as later factors.

Factor analysis of questions about executive and municipal management showed that $65.99 \%$ of variations were explained by two factors. The factor matrix after the varimax rotation is presented in Table 5 . The primary executive and municipal management factors related to people's perspectives about Isfahan air pollution are as follows:

The first factor included the gasoline quality, the quality of cars manufactured in the country, and the suitability of the approved rules and regulations for air pollution abatement and their enforcement guarantee (with $45.52 \%$ of variations).

The second factor comprised the closure of large industries located around Isfahan explained $20.47 \%$ of variations. According to the results of Chi-square test, $65.40 \%$ and $47.78 \%$ of respondents were unsatisfied with the quality of cars and gasoline produced in the country. Moreover, about $30 \%$ of respondents were unsatisfied with the present rules and regulations aimed at reducing air pollution. It could be outlined that the most important requests of Isfahanies from executive and municipal management in reducing air pollution are to test and ensure the quality of gasoline, improve the quality of car manufacturing, and amend air quality laws and regulations.

Concerning reducing air pollution, it was found that $74.644 \%$ of changes could be explained by four factors. The factor loadings after the varimax rotation are also shown in Table 6. The main factors for air pollution control based on the Isfahanian citizens are as follows:

The first factor included the construction of Isfahan subway and expansion of green spaces which ranked high important by $31.69 \%$ and $44.39 \%$ of Isfahanian citizens, respectively.

The second factor comprised the strategy of municipal management and expansion of public transportation network/ placing environmental and energy conservation labels on products which received a $19.23 \%$ share in factor analysis. Improving municipal management and the high importance of environmental conservation labels were identified by $20.58 \%$ and $15.30 \%$ of respondents as influential for enhancing air pollution, respectively.

The third factor encompassed the production of highquality gasoline and exchange of old cars with new ones and improving the people's culture in using public transportation (with $17.55 \%$ variations in factor analysis). Nearly 
Table 6 Factor loadings of air pollution abatement strategies after the varimax rotation

\begin{tabular}{|c|c|c|c|c|}
\hline \multirow[t]{2}{*}{ Item } & \multicolumn{4}{|c|}{ Component } \\
\hline & 1 & 2 & 3 & 4 \\
\hline Industrial performance improvement & -0.054 & 0.040 & 0.013 & 0.939 \\
\hline High-quality gasoline and exchange of old car & 0.136 & -0.221 & 0.794 & 0.324 \\
\hline $\begin{array}{l}\text { Improving the people's culture in using public } \\
\text { transportation }\end{array}$ & -0.113 & 0.246 & 0.741 & -0.358 \\
\hline Improving municipal management & 0.061 & 0.756 & 0.069 & -0.065 \\
\hline Environmental conservation labels & -0.141 & 0.809 & -0.076 & 0.081 \\
\hline Construction of Isfahan subway & 0.851 & 0.021 & 0.151 & -0.087 \\
\hline Expansion of green areas & 0.856 & -0.094 & -0.123 & 0.044 \\
\hline
\end{tabular}

Table 7 Factor loadings of responsibility in controlling air pollution condition and the people's satisfaction from air pollution-reducing sections after the varimax rotation

\begin{tabular}{llrrc}
\hline \multirow{2}{*}{ Item } & $\begin{array}{l}\text { Responsibil- } \\
\text { ity/ Satisfac- } \\
\text { tion }\end{array}$ & \multicolumn{4}{l}{ Component } \\
\cline { 3 - 5 } & & & & \\
\hline Isfahan Municipality & Responsibility & 0.213 & 0.782 & - \\
& Satisfaction & 0.753 & -0.164 & 0.165 \\
Isfahan Department & Responsibility & 0.751 & -0.083 & - \\
of Environment & Satisfaction & 0.755 & 0.245 & -0.084 \\
(DoE) & & & & \\
Industries & Responsibility & 0.307 & 0.740 & -0.354 \\
& Satisfaction & 0.241 & -0.636 & - \\
Citizens & Responsibility & -0.790 & -0.053 & - \\
& Satisfaction & -0.190 & 0.765 & 0.393 \\
TV-radio broadcasting & Responsibility & - & - & - \\
& Satisfaction & 0.103 & 0.023 & 0.896 \\
\hline
\end{tabular}

$39.05 \%$ of people surveyed reported that improving the quality of gasoline and cars are the most important items contributing to air pollution reduction. On the contrary, $27.70 \%$ of respondents pointed to improving the people's culture in using public transportation as the most important factor.

The fourth factor identified Industrial performance improvement for emitting lower levels of air pollution as the least important factor with $16.32 \%$ variations in factor analysis. $44.85 \%$ of people believed that this item can contribute significantly to lowering air pollution.

Factor analysis of the responsibility for controlling air pollution condition (Table 7) revealed that two factors could explain $57.94 \%$ of variations. Based on the perception of respondents, citizens and later Isfahan department of environment (DoE) have the highest responsibility for controlling air pollution conditions and account for $32.31 \%$ of variations, followed by Isfahan Municipality and industries with $25.63 \%$ of variations. Factor analysis after the varimax rotation showed a positive role for Isfahan DoE and Isfahan Municipality and a negative one for citizens and industries in exercising responsibility for controlling air pollution conditions. The results of Chi-square showed that $47.63 \%$ of Isfahanies believe that Isfahan DoE should hold the highest responsibility in controlling air pollution conditions, followed by industries, Isfahan municipality, and citizens with a share of $26.58 \%, 25.98 \%$, and $25.20 \%$, respectively.

Regarding the people's satisfaction from the performance of sections involved in air pollution control, Isfahan DoE ranked first accounts for $25.56 \%$ of variations. With a slight difference, industries and the people's performance in using public transportation ranked second that explain $24.41 \%$ of variations, and TV-radio broadcasting and other media took the third priority with $22.33 \%$ of variations in factor analysis (Table 7). The results of Chi-square showed that the people's satisfaction from the involved sections is as follows: $33.42 \%$ from TV-radio broadcasting, $30.53 \%$ from Isfahan Municipality, $20.79 \%$ from Isfahan DoE, $16.84 \%$ from the people's performance in using public transportation, and $13.16 \%$ from industries. According to these results, TV-radio broadcasting, Isfahan Municipality, and Isfahan DoE were the foremost three organizations in achieving the people's satisfaction.

\subsection{Correlation between $\mathrm{AQI}$ and the questionnaire responses}

\subsubsection{Temporal changes in AQI}

Table 8 shows that the mean AQI index also increased significantly $(P$-Value $<0.0001)$ from 77.61 to 93.46 in the period of 2008-2017 ( $P$-Value $<0.0001)$; whereas, $84 \%$ of respondents believed that Isfahan had a polluted or heavily polluted air during the past 5 years from 2012 to 2017 .

\subsubsection{AQI index and the pollution source}

According to our findings, the relationship between mean AQI and respondent's opinions on the pollution sources obtained via questionnaire was significant 
Table 8 Changes in AQI from 2008 to 2017

\begin{tabular}{rcc}
\hline Mean AQI \pm SE & No & Year \\
\hline $100.00 \pm 1.09$ & 365 & 2008 \\
$105.45 \pm 1.66$ & 363 & 2009 \\
$102.44 \pm 1.50$ & 365 & 1010 \\
$88.11 \pm 1.50$ & 341 & 2011 \\
$77.61 \pm 1.38$ & 365 & 2012 \\
$92.86 \pm 2.30$ & 276 & 2013 \\
$103.62 \pm 1.45$ & 365 & 2014 \\
$95.42 \pm 1.20$ & 365 & 2015 \\
$83.69 \pm 1.12$ & 365 & 2016 \\
$93.45 \pm 0.50$ & 365 & 2017 \\
\hline
\end{tabular}

$(P$-Value $<0.045)$. The two main pollution sources which contributed a significant role in AQI changes over the past years were as follows: (1) low-quality gasoline and cars and the vast number of cars, and (2) natural factors such as Zayandehroud River dryness, dust, and haze particles (Table 9).

\subsubsection{AQI and pollution impacts}

The results showed that the relationship between AQI and respondent's opinions on the impacts of air pollution gained via a questionnaire were not significant for the entire study period of 10 years $(P$-Value $=0.220)$, however, was highly significant for the period 2008-2015 $(P$-Value $=0.032)$. Table 10 shows the crucial role of $A Q I$ in susceptibility to mental diseases, neurological disorders, decreasing people's happiness $(P$-value $=-0.026)$ as well as increasing aggression and street violence $(P$-value $=0.079)$. Furthermore, the impact of air pollution in Isfahan on historical monuments was found to be remarkable $(P$-value $=0.044)$.

\section{Discussion}

The present study was conducted to follow the links from public perception, attitude, and knowledge on air pollution toward pro-environmental behavior for reducing the air pollution level. Initially, it was tried to indicate how

Table 9 Regression results between AQI and responses given to pollution sources

\begin{tabular}{|c|c|c|c|c|c|}
\hline \multirow[t]{2}{*}{ Model } & \multicolumn{2}{|c|}{$\begin{array}{l}\text { Unstandardized } \\
\text { Coefficients }\end{array}$} & \multirow{2}{*}{$\begin{array}{l}\text { Standard- } \\
\text { ized Coef- } \\
\text { ficients } \\
\text { Beta }\end{array}$} & \multirow[t]{2}{*}{$\mathrm{t}$} & \multirow[t]{2}{*}{ Sig } \\
\hline & $\bar{B}$ & Std. Error & & & \\
\hline Constant & 79.937 & 7.246 & - & 11.031 & 0.000 \\
\hline Industries & -0.379 & 0.947 & -0.023 & -0.400 & 0.689 \\
\hline Poor-quality gasoline and cars and the high number of vehicles & 2.258 & 0.994 & 0.131 & 2.271 & 0.024 \\
\hline Drying up of Zayandehroud River, dust, and haze particles & 1.965 & 0.943 & 0.118 & 2.083 & 0.038 \\
\hline $\begin{array}{l}\text { Improper municipal management, poor performance of available structures (such as } \\
\text { universities and broadcasting companies) }\end{array}$ & 0.049 & 0.996 & 0.003 & 0.049 & 0.961 \\
\hline $\begin{array}{l}\text { Non-compliance with environmental laws and regulations as well as public culture in } \\
\text { using vehicles }\end{array}$ & 1.137 & 0.946 & 0.072 & 1.202 & 0.230 \\
\hline Arid-warm climate of Isfahan & 0.705 & 1.283 & 0.030 & 0.550 & 0.583 \\
\hline
\end{tabular}

Table 10 Regression results between $\mathrm{AQI}$ and responses given to the impacts of air pollution

\begin{tabular}{|c|c|c|c|c|c|}
\hline \multirow[t]{2}{*}{ Model } & \multicolumn{2}{|c|}{$\begin{array}{l}\text { Unstandardized Coef- } \\
\text { ficients }\end{array}$} & \multirow{2}{*}{$\begin{array}{l}\text { Standardized } \\
\text { Coefficients } \\
\text { Beta }\end{array}$} & \multirow[t]{2}{*}{$\mathrm{t}$} & \multirow[t]{2}{*}{ Sig } \\
\hline & $\mathrm{B}$ & Std. Error & & & \\
\hline Constant & 115.282 & 7.216 & - & 15.977 & 0.000 \\
\hline Multiple sclerosis (MS) & -0.459 & 1.468 & -0.0020 & -0.313 & 0.755 \\
\hline $\begin{array}{l}\text { Mental diseases, neurological disorders, } \\
\text { decreasing people's happiness }\end{array}$ & -4.166 & 1.860 & -0.164 & -2.240 & 0.0 .026 \\
\hline Respiratory discomfort & -1.912 & 1.849 & -0.0070 & -1.034 & 0.302 \\
\hline Hair and skin & -0.460 & 1.764 & -0.0 .018 & -0.261 & 0.0 .794 \\
\hline Increasing aggression and street violence & 3.014 & 1.709 & 0.130 & 1.764 & 0.0 .079 \\
\hline Tourism & -2.222 & 1.516 & -0.0098 & -1.466 & 0.143 \\
\hline Historical monuments & 2.667 & 1.322 & -0127 & 2.017 & 0.044 \\
\hline
\end{tabular}


much Isfahanian have knowledge about the problem of the air pollution in the city and its impacts, then requested from citizen to select a strategy that they feel it is helpful for the control of this problem. One of the advantages of this study is prioritizing people's perspectives on air pollution management in Isfahan including sources of air pollution, affectivity of the executive management's role, air pollution control plans, the responsibility of people/ managers about air pollution, and the people's satisfaction about the performance of actions involved in air pollution management. This can help the managers and decisionmakers to come up with the strategies which will be supported by the citizens.

The results of this research showed that the awareness of Isfahanies regarding air quality condition and its changes over the past few years accord well with changes in $A Q I$ values, indicating that direct experiences and the evident impacts of air pollution on human health are the first and most important source of awareness among the people of Isfahan. It was also found by the results of the questionnaire-based survey that Isfahanies feel seasonal and diurnal changes in air pollution because the quality of air is more unpleasant during summer and winter compared to other seasons. Such a conclusion was corroborated by similar studies in which scientists showed that factors such as sunlight intensity, high temperature, decreasing precipitation, air dryness, and air instability during summer as well as air stability, temperature inversion, and intensification of polluting emissions by industries involved with fossil fuel-related processes during winter have the potential to rise air pollution level and decrease people's satisfaction about air pollution [38, 39]. Besides, Isfahanian people stated that air pollution level is higher in the early morning, noon, and, especially, afternoon hours. The high traffic load during these hours is probably the main unfavorable air quality factor felt by people. Walter et al. [40] investigated the public reaction to air pollution in Nashville, Tennessee and found a close correspondence between the people's concern and air pollution level (especially diurnal air quality index) which indicates the increasing awareness of people in the area. Chen et al. [41] found that an increase in air pollution reduced the level of life satisfaction in Chinese citizens via environmental perceptions so citizens living in districts with poorer air quality are less satisfied with law enforcement. Bickerstaff and Walker [1] assessed the people's perception of air pollution in Birmingham, UK and found a tendency in people to engage with nature, green areas and live in areas free from air pollution. By contrast, negative reactions such as leaving waste on the street, crime, and being unresponsive to the environment were more noticed in areas in which people show less commitment to keeping the outdoor environment clean. Such a concern and dissatisfaction about air quality were found to be higher in highly polluted areas including the central part of the city where population and traffic are relatively high and southeastern and northwestern parts surrounded by industrial centers. These conclusions were also proved by other researchers [4, 40, 42].

Moreover, it was found that the awareness about air pollution risks and threats regarding respiratory diseases among Isfahanies has been increased in recent years. In the present study, the significant relationship found between mean AQI and the respondents' opinions about the impacts of air pollution can be regarded as a confirmation on the people's concern regarding the role of air pollution in increasing susceptibility to physical and mental diseases. Several research works on the relationship between the concentration of environmental pollutants and vulnerability to mental, physical, and neurological diseases which has clarified some latent aspects of the impacts of air pollution on people's health $[13,33$, 43]. The increase of awareness and perception of people about air pollution especially its risks and hazards can awake public opinion to be more responsible for improving air quality regarding their significant role in mitigating air pollution. This issue intensively influences on encouraging the public to participate in environmental protection plans or their willingness to pay for improving air quality $[9,26]$. Chin et al. [22] reported that Malaysians who experienced respiratory illness in their family were more willing to pay for air pollution control than the others. Duan and Sheng [19] investigated the relationship between environmental knowledge and pro-environmental behavior using national survey data in China. They found that the individual environmental knowledge (i.e., living conditions knowledge) may act as a strong driver for the proenvironmental behaviors included private (personal activities at a household level) and public (at a general level) activities. While professional environmental knowledge (i.e., ecological and scientific knowledge) has only a direct effect on public pro-environmental behavior. Wang et al. [44] pointed out that the public willingness to participate in air pollution control in the Beijing-Tianjin-Hebei region is influenced by income level, occupation, the awareness of air pollution, and governmental actions.

In our studied community, the perception and tendency to the protection of the environment were more evident in men than women which can be ascribed to the fact that men usually face higher exposure to pollutants by spending longer time outside. Studies such as Levine and Strube [16] in Washington University and also Chin et al. [22] in peninsular Malaysia support this finding. They reported that males have higher environmental knowledge than females so indicate more environmentally friendly behaviors. However, several studies have pointed 
out that women tend to express a higher level of concern about environmental hazards than men as they may more sensitive and responsible about environmental issues [7, 21, 31]. Seif and Nematolahi [3] examined the effective factors on environmentally friendly behaviors among high school students in Shiraz, Iran, and found that student girls express higher levels of concern about environmental issues so tend to express more pro-environmental behavior than student boys. Duan and Sheng [19] and Xiao and Hong [45] indicated that females better perceive the environmental values so they were more engaged in private pro-environmental behaviors than men among the Chinese public. Such differences may be associated with different roles of women who act usually as caregivers and men act as breadwinners.

The findings showed that people consider natural factors such as Zayandehroud dryness (intensified by the arid-warm climate of Isfahan) and, thereafter, improper municipal management, transportation, and industries as the main worrying contributing factors to air pollution. Furthermore, the correlation between AQI values and respondent's opinion on air pollution source identification further elucidated the role of several factors such as low quality of gasoline and cars, a large number of cars, and natural factors (such as dust particles and drying up of Zayandehroud River) in worsening air quality of Isfahan. Karimi et al. [29] revealed that arid and semi-arid climates (low precipitation and high temperature) have a significant impact on increasing the level of air pollution in Isfahan Province.

The effect of natural factors such as dust and particle matters ( 2.5 and $10 \mu \mathrm{m}$ ) in the country's large cities such as Isfahan has acquired special attention because a considerable proportion of these matters has stemmed from air dryness and encroachment of mobile sands. The importance of dust and haze particles in Isfahan was first raised in 2007, but it lost attention quickly until present which has again emerged as one of the most tangible environmental-anthropogenic crises of everyday life with significant economic impacts. Being located in the central plateau of Iran with an arid-warm climate, high evatransportation (about $3500 \mathrm{~mm}$ per year), poor vegetation cover, and intense winds as natural factors [46] and overexploitation of underground waters, degradation of forests and rangelands, and development of sand mines as well as gypsum and brick kilns as anthropogenic factors which are particularly influential in eastern Isfahan [47] have led to increasing dust storms blowing through the city and jeopardizing people's health over the past years.

Besides the ravaging impacts of dust and haze storms on air and semi-arid regions of the country, studies and special investigations have outlined that the most profound and common air pollutants in big cities like Isfahan come from stationary (domestic, commercial, and industrial) and mobile (transportation vehicles) sources, so that from the total amount of pollutants emitted into the ambient air, $13 \%$ resulted from urban industries, $11 \%$ from domestic sources, and $76 \%$ from traffic exhausts [24]. Several national and international reports pointed out that transportation and industry are the most important sources of pollution around the globe respectively [48]. In Iran, transportation comprises the largest share of air pollution by producing nearly $64.3 \%$ of the total emission of nitrogen oxides, $29.3 \%$ of sulfur dioxide, $27.5 \%$ of carbon dioxide, $24.8 \%$ of sulfur trioxide, $98.6 \%$ of carbon monoxide, $96.396 \%$ of unburned hydrocarbons, and $79.2 \%$ of particle matters [49]. In a similar study, Cisneros et al. [31] assessed the public perception from air quality and pollution sources in San Joaquin, California and found that it is important to provide clarification about air pollution sources and their respective share because the real contribution of various sources in air pollution was different from the people's perspectives. For example, the top-three pollution sources were supposed by people to be cars, particle matters, and industries whereas, in reality, they were found to be agriculture, cars, and pollution resulted from the Gulf, respectively.

Among the practical air pollution abatement strategies to be implemented in Isfahan, the people's opinions were more leaned toward subway construction, development of green areas, and improving municipal management. Since modern transportation systems such as trolley and subway have started to be constructed in Isfahan, the majority of transportation vehicles are now spewing out high levels of emissions. This has evoked wide public concern and people believe that the running of the subway would serve as a major contributor to decreasing the use of personal cars and, in turn, reducing air pollution. Yazdanibakhsh et al. [26] in their study on investigating the priorities in air pollution management in Isfahan, Iran, reported that developing and improving the public transportation such as the establishment of subway facilities should be the first priority of the decision-makers and managers to mitigate the air pollution in Isfahan.

It should be noted that the large and growing number of cars in the city $(1,168,000$ registered gasoline cars by 2008) [24] still urges to improve gasoline quality and optimize energy efficiency [50,51]. The importance of considering this issue was further highlighted by the results of this study, indicating that $44.82 \%$ of people frequently use personal vehicles to commute within the city. In recent years, however, air pollution and the concentration of carbon monoxide, sulfur dioxide, and nitrogen oxides in big cities like Isfahan have been managed by laying out some effective strategies such as supplying them with EuroIV quality gasoline, giving special attention to the fuels 
utilized in industries (as stationary pollution sources) by replacing them with non-fossil fuels (e.g., replacing mazut with natural gas at Isfahan power plants). In the study of Mohammadkhah et al. [52] on evaluating the knowledge and attitudes of the students of Shahid Beheshti University of Medical Sciences (SBMU) about the air pollution sources and solutions in Tehran where the improvement of the quality of fuel, vehicles, and development of green space were the suggested solutions to mitigate the air pollution.

In addition to the above mentioned issues, we conclude the following basic problems lead to unhealthy air quality in large cities such as Isfahan:

1. Although there are many rules and regulations for protecting the environment and reducing the air pollution, these laws are either not deterrent enough or not properly enforced.

2. It seems each responsible organization, company, administration, or people for improving the quality of the air, regards the other sectors to be responsible for the present status and intends to exonerate rather than to accuse.

3. The level of awareness and knowledge of people about the air quality and its related impacts are not well enough. This issue has led not only to know of their duties but also the proper ways of requesting the custodians.

Therefore, the following solutions can be considered as key solutions to the present status of air quality in big cities:

1. Execution of existing laws and drafting other incentive and preventive laws in the form of a comprehensive pollution prevention plan for improvement of the air quality.

2. Integrated management between lawmakers, decision-makers, and people for solving the air pollution problem.

3. Helping to improve the attitude, understanding, awareness, and knowledge of people about the importance of air quality and their duties and custodians about air pollution by implementing educational and promotional programs and the proper use of media tools.

According to the findings, it should be considered that raising citizen's awareness and their engagement is an initial solution to the air pollution problem in which its prerequisite is to outline effective policies that motivate and shape the behavior of people. This conclusion was confirmed by other research works on public perception and engagement practices in air pollution management
[16-18]. Therefore, it is important to awaken public opinion regarding the health hazards of air pollution, its triggering factors, and controlling strategies to better participate in air pollution management. However, the next step for the integrated management of air pollution is that the control measures should be done by managers and decision-makers. Wang et al. [44] reported that as air pollution control is a large-scale task and different sectors are involved, the public individual participating and governmental actions can help together to reach a win-win solution in improving the air quality.

Table 11 shows the main sources of the concerns and dissatisfaction of Isfahanian citizens about the air quality, and also the major control measures to reduce air pollution related to each source were based on the finding in the present study as well as previously published research works $[26,29,47,50,51,53]$. This may help the decisionmakers to pay attention to the most important challenges facing people to prioritize the main strategies to reduce air pollution. As it is mentioned in Table 11, raising the level of individual education may have a significant role in air pollution control especially related to the use of transportation (private and public). This can help people to perceive their commitment and tasks toward environmental protection. This issue in other research works was also confirmed that environmental education gives people a deeper perception about the environmental pollution to follow more pro-environmental behavior $[19,52]$. Zhao et al. [54] found that public education about haze pollution is needed not only to increase the basic knowledge of the problem but also to improve self-care and reduce the exposure risk.

We believed that in this study we tried to clarify the importance and necessity of public participation in air pollution control. However, there are some limitations and shortcomings. An important limitation of this study is that the selected sample size is fairly small and may not be representative of the population in Isfahan city, so the results must be interpreted with caution. Second, the surveys were conducted in the summer and fall of 2016-2017. We assume that people's opinion might be different a bit in winter and spring as the highest and lowest level of air pollution, respectively. Third, other influencing parameters on public perception like subjective norms, culture, occupational status, and income should be considered.

\section{Conclusions}

The main focus of the present paper was to express the importance of social dimension associated with air pollution such as the perception, incentives, awareness, and responsibility of the public to air pollution in Isfahan city 
Table 11 Summary of the main sources of air pollution in Isfahan city and the major control measures to reduce air pollution burden (based on Isfahanian citizens opinions and previously published research works) $[26,29,47,50,51,53]$

\begin{tabular}{|c|c|}
\hline Main sources of air pollution & Major control measures to reduce air pollution \\
\hline $\begin{array}{l}\text { Zayandehroud dryness and the arid-warm climate of Isfahan lead to } \\
\text { increase of dust and haze emission in air }\end{array}$ & $\begin{array}{l}\text { Development of vegetation cover for control of winds and haze } \\
\text { emission } \\
\text { Prevention of over-exploitation of underground waters } \\
\text { Prevention of degradation of rangelands and plant cover } \\
\text { Educating and encouraging people for the reduction in water con- } \\
\text { sumption and following water conservation }\end{array}$ \\
\hline High population and traffic in the central part of the city & $\begin{array}{l}\text { Improve emission standards for vehicles } \\
\text { Improve gasoline and diesel quality } \\
\text { Restrict the use of private cars } \\
\text { Reduce the registration of additional cars } \\
\text { Promoting clean energy vehicles } \\
\text { Promoting public transportation } \\
\text { Providing facilities for public welfare in the whole city } \\
\text { Educating and encouraging people to the use of clean vehicles and } \\
\text { public transportation }\end{array}$ \\
\hline $\begin{array}{l}\text { Presence of industries and factories in southeastern and northwest- } \\
\text { ern part }\end{array}$ & $\begin{array}{l}\text { Properly locating industrial areas } \\
\text { Use of air cleaning devices ( separators or collectors) } \\
\text { Change in fuel type (use of natural gas as a clean fuel) } \\
\text { Substitution of highly polluted input materials } \\
\text { Modification or change of the industrial process or equipment }\end{array}$ \\
\hline
\end{tabular}

as a highly air-polluted city in Iran. It is found that the proenvironmental behaviors of people significantly depend on their perception of air pollution as public engaging in air pollution control plans will be obtained by an increase of their awareness about air quality status, its health-related consequences, and high level of citizen's responsibility. This clarification makes people aware and inspires them to do activities to decline the air pollution burden and prevent some economic damages of air pollution to public health and the environment. The role of media (TV, radio, newspapers, and virtual media) can play a vital role in improving pro-environmental behaviors. Moreover, the role of managers and decision-makers in the integrated management of air pollution to provide mitigating infrastructures must be followed to attract people's satisfaction.

\section{Compliance with ethical standards}

Conflict of Interest The authors declare that they have no conflict of interest. All procedures performed in this study involving human participants were in accordance with the ethical standards of the institutional and/or national research committee. Informed consent was obtained from all individual participants included in the study.

\section{Appendix}

See Table 12. 
Table 12 Survey questionnaire about air pollution

The awareness level of Isfahanies about air pollution

People's perspectives regarding air pollution management in Isfahan

Very low Low Moderate High Very high

The relationship between education and willingness-to-pay for reducing air pollution

Under diploma Diploma Advanced diploma BSc MSc PhD

People's satisfaction from the performance of sections involved in air pollution abatement

Isfahan Municipality. Isfahan Department of Environment (DoE). Industries. Citizens TV-radio broadcasting

Pollution impacts

Multiple sclerosis (MS). Mental diseases, neurological disorders, decreasing people's happiness. Respiratory discomfort. Hair and skin. Increasingaggression and street violence. Tourism. Historical monuments
Source identification

Industries. Poor-quality gasoline and cars and the high number of vehicles. Improper municipal management, poor performance of available structures (such as universities and broadcasting companies). Non-compliance with environmental laws and regulations as well as public culture in using vehicles. Drying up of Zayandehroud River. Arid-warm climate of Isfahan

Executive management

Gasoline quality. Quality of manufactured cars. Closure of large industries. Suitability of the approved rules and regulations for air pollution abatement. Enforcement guarantee of rules

Air pollution control and improvement

Industrial performance improvement. High-quality gasoline and exchange of old car. Improving the people's culture in using public transportation. Improving municipal management. Placing environmental and energy conservation labels on products. Construction of Isfahan subwayExpansion of green areas

Responsibility for controlling air pollution

Isfahan Municipality. Isfahan Department of Environment (DoE). Industries. Citizens

\section{References}

1. Bickerstaff K, Walker G (2001) Public understandings of air pollution: the 'localisation' of environmental risk. Global Environ Change 11(2):133-145

2. D'Amato G, Cecchi L, D'Amato M, Liccardi G (2010) Urban air pollution and climate change as environmental risk factors of respiratory allergy: an update. J Investig Allergol Clin Immunol 20:95-102

3. Seif MH, Nematolahi MA S (2019) The effective factors on environmentally friendly behavior: a case study. University of Nebraska - Lincoln Library Philosophy and Practice (e-journal) ISSN 1522-0222

4. Gupta U (2008) Valuation of urban air pollution: a case study of Kanpur City in India. Environ Res Econ 41(3):315-326

5. Anderson HR (2009) Air pollution and mortality: A history. Atmos Environ 43(1):142-152

6. Hodgson A, Hitchings R (2018) Urban air pollution perception through the experience of social practices: Talking about breathing with recreational runners in London. Health \& place 53:26-33

7. Oltra C, Sala R (2014) A review of the social research on public perception and engagement practices in urban air pollution, New strategies for public engagement in urban air pollution control. Informes Técnicos Ciemat, Ciudad Universitaria, 28040-Madrid, España

8. West JJ, Cohen A, Dentener F, Brunekreef B, Zhu T, Armstrong B (2016) What we breathe impacts our health: improving understanding of the link between air pollution and health. Environ Sci Technol 50(10):4895-4904

9. Corcoran PB, Osano PM (2009) Young people, education, and sustainable development: exploring principles, perspectives, and praxis. Wageningen Academic Publishers, The Center for Environmental and Sustainability Education, Florida Gulf Coast University, USA
10. Tu Z, Hu T, Shen R (2019) Evaluating public participation impact on environmental protection and ecological efficiency in China: Evidence from PITI disclosure. China Econ Rev 55:111-123

11. Xu J, S. CC, Zhu K, (2017) Concern or apathy: the attitude of the public toward urban air pollution. J Risk Res 20(4):482-498

12. Atari DO, Luginaah IN, Fung K (2009) The relationship between odour annoyance scores and modeled ambient air pollution in Sarnia, "'Chemical Valley"', Ontario. Int J Environ Res Public Health 6(10):2655-2675

13. Saksena S, Prasad RK, Shankar VR (2007) Daily exposure to air pollutants in indoor, outdoor and in-vehicle micro-environments: a pilot study in Delhi. Indoor Built Environ 16(1):39-46

14. Chase SK, Levine A (2018) Citizen science: exploring the potential of natural resource monitoring programs to influence environmental attitudes and behaviors. Conserv Lett 11(2):382-402

15. Moradhaseli S, Ataei P, Norouzi A (2017) Analysis of students environmental behavior in the Agriculture College of Tarbiat Modares University, Iran (application of Planned Behavior Theory). J Hum Behav Soc Environ 27(7):733-742

16. Levine DS, Strube MJ (2012) Environmental attitudes, knowledge, intentions and behaviors among college students. J Soc Psychol 152(3):308-326

17. Abolhassani L, Afghari AP, Borzadaran HM (2019) Public preferences towards bicycle sharing system in developing countries: The case of Mashhad. Iran Sustainable cities soc 44:763-773

18. Kelly FJ, Fussell JC (2015) Air pollution and public health: emerging hazards and improved understanding of risk. Environ Geochem Health 37(4):631-649

19. Duan W, Sheng J (2018) How can environmental knowledge transfer into pro-environmental behavior among Chinese individuals? Environmental pollution perception matters. J Public Health 26(3):289-300

20. Reames TG, Bravo MA (2019) People, place and pollution: Investigating relationships between air quality perceptions, health concerns, exposure, and individual-and area-level characteristics. Environ Int 122:244-255 
21. Bickerstaff K (2004) Risk perception research: socio-cultural perspectives on the public experience of air pollution. Environ Int 30:827-840

22. Chin YSJ, De Pretto L, Thuppil V, Ashfold MJ (2019) Public awareness and support for environmental protection-A focus on air pollution in peninsular Malaysia. PLoS ONE 14(3):e0212206

23. Kiani K (2014) Investigating population density with air pollution in Isfahan city in 2011, 2nd National Conference on Architecture, Civil and Urban Environment, Faculty of Martyr Mofattah. Hamedan, Iran

24. Zarabi A, Mohammadi JAA (2010) Investigation and evaluation of stationary and mobile resources in air pollution of Isfahan. J Geog Soc Iran 26(8):151-164

25. Jafari N, Ebrahimi AA, Mohammadi A, Hajizadeh Y, Abdolahnejad A (2017) Evaluation of seasonal and spatial variations of Air Quality Index and ambient air pollutants in Isfahan using Geographic Information System. J Environ Health Sustainable Dev 2(2):263-272

26. Yazdanibakhsh F, Salehi E, Faham E, Amin M (2019) Influential factors of air pollution awareness in Isfahan. Iran Pollut 5(2):247-256

27. Deputy of Planning Research and Information Technology of the Municipality of Isfahan (2015) The Atlas of the metropolitan city of Isfahan. Isfahan, Iran

28. Hosseiniebalam F, Ghaffarpasand O (2015) The effects of emission sources and meteorological factors on sulphur dioxide concentration of Great Isfahan. Iran Atmos Environ 100:94-101

29. Karimi H, Soffianian A, Mirghaffari N, Soltani S (2016) Determining air pollution potential using geographic information systems and multi-criteria evaluation: A case study in isfahan province in Iran. Environ Processes 3(1):229-246

30. Kotrlik J, Higgins C (2001) Organizational research: Determining appropriate sample size in survey research appropriate sample size in survey research. Inf Technol Learn Perform J 19:1-43

31. Cisneros R, Brown P, Cameron L, Gaab E, Gonzalez M, Ramondt S (2017) Understanding public views about air quality and air pollution sources in the San Joaquin Valley. J Environ public health, California. https://doi.org/10.1155/2017/4535142

32. Motesaddi S, Hashempour Y, Nowrouz P (2017) Characterizing of air pollution in Tehran: comparison of two air quality indices. Civ Eng J 3(9):749-758

33. Poursafa P, Mansourian M, Motlagh M-E, Ardalan G, Kelishadi $R$ (2014) Is air quality index associated with cardiometabolic risk factors in adolescents? The CASPIAN-III Study. Environ Res 134:105-109

34. Tecer LH (2009) A factor analysis study: Air pollution, meteorology, and hospital admissions for respiratory diseases. Toxicol Environ Chem 91(7):1399-1411

35. Kamaruzzaman SN, Egbu C, Zawawi EMA, Ali AS, Che-Ani AI (2011) The effect of indoor environmental quality on occupants' perception of performance: A case study of refurbished historic buildings in Malaysia. Energy Build 43(2-3):407-413

36. Gerber NL, Price JK (2018) Measures of function and healthrelated quality of life. In: Principles and practice of clinical research. Elsevier, pp303-315

37. Schatz M, Mosen D, Apter AJ, Zeiger RS, Vollmer WM, Stibolt TB, Leong A, Johnson MS, Mendoza G, Cook EF (2005) Relationships among quality of life, severity, and control measures in asthma: an evaluation using factor analysis. J Allergy Clin Immunol 115(5):1049-1055

38. Chen R, Peng RD, Meng X, Zhou Z, Chen B, Kan H (2013) Seasonal variation in the acute effect of particulate air pollution on mortality in the china air pollution and health effects study (CAPES). Sci Total Environ 450:259-265
39. Jayamurugan RB, Kumaravel S, Palanivelraja CBM (2013) Influence of temperature, relative humidity and seasonal variability on ambient air quality in a coastal urban area. Int J Atmos Sci. https://doi.org/10.1155/2013/264046

40. Walter SS, Schueneman JJ, Zeidberg MD, Louis D (1964) Public reaction to air pollution in Nashville. Tenn J Air Pollut Control Assoc 14(10):418-423

41. Chen L, Zhang J, You Y (2020) Air pollution, environmental perceptions, and citizen satisfaction: A mediation analysis. Environ Res 184:109287

42. Mumtaz NA, Yadav Izhar T (2017) Comparative assessment of air quality of major cities of Uttar Pradesh. India 3(4):220-225

43. Bazyar J, Pourvakhshoori N, Khankeh H, Farrokhi M, Delshad V, Rajabi E (2019) A comprehensive evaluation of the association between ambient air pollution and adverse health outcomes of major organ systems: a systematic review with a worldwide approach. Environ Sci Pollut Res 26(13):12648-12661

44. Wang B, Hong G, Qin T, Fan W-R, Yuan X-C (2019) Factors governing the willingness to pay for air pollution treatment: $A$ case study in the Beijing-Tianjin-Hebei region. J Cleaner Prod 235:1304-1314

45. Xiao C, Hong D (2018) Gender differences in environmental behaviors among the Chinese public: Model of mediation and moderation. Environ Behav 50(9):975-996

46. Zaki M, Ezatian V, Zeraei H (2015) Zoning the concentration of dust in the metropolis of Isfahan and its changes, International conference on science, engineering and environmental technologies, Tehran, Faculty of Environment. University of Tehran, Tehran, Iran

47. Shah-noushi M, Jalalian A (2013) Dust crisis and drought effects in Gavkhoni Wetland and Isfahan Province, Third conference on environmental planning and management. University of Tehran, Tehran, Iran

48. Howel D, Moffatt S, Bush J, Dunn CE, Prince H (2003) Public views on the links between air pollution and health in Northeast England. Environ Res 91(3):163-171

49. Deputy of electricity and energy affairs (2012) The energy balance sheet. Office of planning for electricity and energy, Tehran, Iran

50. Mansouri B, Hamidian AH (2013) Assessment of the air quality of Isfahan city, Iran, using selected air quality parameters. Iran J Toxicol 7(21):482-484

51. Khorasani N, Cheraghi M, Nadafi K, Karami M (2002) Assessment and comparison of air quality in Tehran and Isfahan cities in 1999 and presenting improvement solutions. Iran Nat Res J 55(4):559-568

52. Mohammadkhah $F$, Heydarabadi AB, Hadei $M$, Rakhshanderou S, Vaziri MH, Shahsavani A (2017) Knoweledge and attitude of university students about air pollution problem in Tehran, Iran (2015-2016). J Air Pollut Health 2(2):81-86

53. Ghorani-Azam A, Riahi-Zanjani B, Balali-Mood M (2016) Effects of air pollution on human health and practical measures for prevention in Iran. Journal of research in medical sciences: J Isfahan Univ Med Sci 21:1-12

54. Zhao M, Zhang M, Ying J, Wang S, Shi Y, Li H, Li Y, Xing Z, Sun J (2019) Knowledge, attitudes, practices and information demand in relation to haze in China: a cross-sectional study. BMC public health 19(1):1-11

Publisher's Note Springer Nature remains neutral with regard to jurisdictional claims in published maps and institutional affiliations. 